\title{
Surface Wave Velocity-Stress Relationship in Uniaxially Loaded Concrete
}

\author{
Shokouhi, Parisa; Zoëga, Andreas; Wiggenhauser, Herbert; Fischer, Gregor
}

Published in:

A C I Materials Journal

Publication date:

2012

Document Version

Publisher's PDF, also known as Version of record

Link back to DTU Orbit

Citation (APA):

Shokouhi, P., Żoëga, A., Wiggenhauser, H., \& Fischer, G. (2012). Surface Wave Velocity-Stress Relationship in Uniaxially Loaded Concrete. A C I Materials Journal, 109(2), 141-148.

\section{General rights}

Copyright and moral rights for the publications made accessible in the public portal are retained by the authors and/or other copyright owners and it is a condition of accessing publications that users recognise and abide by the legal requirements associated with these rights.

- Users may download and print one copy of any publication from the public portal for the purpose of private study or research.

- You may not further distribute the material or use it for any profit-making activity or commercial gain

- You may freely distribute the URL identifying the publication in the public portal

If you believe that this document breaches copyright please contact us providing details, and we will remove access to the work immediately and investigate your claim. 


\title{
Surface Wave Velocity-Stress Relationship in Uniaxially Loaded Concrete
}

\author{
by Parisa Shokouhi, Andreas Zoëga, Herbert Wiggenhauser, and Gregor Fischer
}

\begin{abstract}
The sonic surface wave (or Rayleigh wave) velocity measured on prismatic concrete specimens under uniaxial compression was found to be highly stress-dependent. At low stress levels, the acoustoelastic effect and the closure of existing microcracks results in a gradual increase in surface wave velocities. At higher stress levels, concrete suffers irrecoverable damage: the existing microcracks widen and coalesce and new microcracks form. This progressive damage process leads first to the flattening and eventually the drop in the velocity-stress curves. Measurements on specimens undergoing several loading cycles revealed that the velocities show a stress-memory effect in good agreement with the Kaiser effect. Comparing the velocities measured during loading and unloading, the effects of stress and damage on the measured velocities could be differentiated. Moreover, the stress dependency of surface wave velocity proved to be direction-dependent. The velocity increases and decreases the most when measured parallel and perpendicular to the loading axis, respectively.
\end{abstract}

Keywords: acoustic emission; acoustoelasticity; microcracking; surface waves; velocity measurement.

\section{INTRODUCTION}

The deterioration of concrete due to excessive loading, freezing and thawing, corrosion of reinforcement, or alkalisilica reaction (ASR) starts with subtle changes in its microstructure and microcracking. If the damage mechanism persists, the density of microcracks gradually increases. As the damage progresses, the microcracks grow, widen, join together, and eventually develop into macrocracks. In most cases, the cracks become visible only after the damage is already at a critical level. If the deterioration process goes undetected until reaching this critical stage, major repairs should be undertaken to prevent the premature failure of concrete structural members. An early detection of damage is necessary to enable taking condition-based preventive maintenance measures and avoid the high cost of demolition and reconstruction projects.

To estimate the level of damage and the remaining loading capacity of a concrete structural member at the early stages of the deterioration process, routine inspection of the in-place condition is necessary. Such an inspection is most effective if the in-place material gradual degradation and level of stress can be evaluated nondestructively without harming the structure itself. As such, advanced nondestructive testing (NDT) techniques enabling early detection and characterization of concrete deterioration are in high demand.

The potential of surface wave velocity measurements for characterizing the level of damage and stress in concrete is investigated in the experimental study presented herein. The effects of stress-induced damage on sonic surface wave velocity were measured in concrete specimens undergoing cycles of uniaxial compression. This study gives a review of

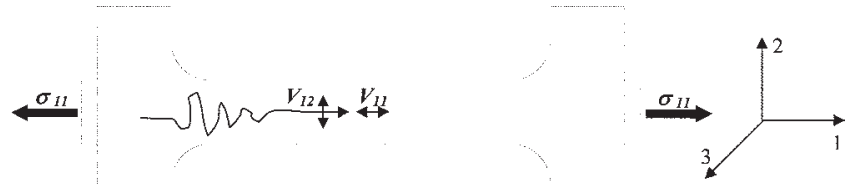

Fig. 1-Ultrasonic wave propogation in direction of loading in uniaxially loaded column.

the essential background information, followed by a description of the experiments and a discussion of their results.

\section{Acoustoelasticity}

\section{BACKGROUND}

The changes in the propagation velocities of ultrasonic waves due to the state of strain (or stress) in a nonlinear elastic solid are generally referred to as acoustoelastic effects. ${ }^{1}$ Consider an elastic column made of nonlinear constituent material of initial (stress-free) compression wave velocity of $V_{P}$ and shear wave velocity of $V_{S}$ (Fig. 1). According to the theory of acoustoelasticity, once this column is subjected to uniaxial normal stress $\sigma_{11}$, the velocity of longitudinal and transversal ultrasonic waves, $V_{11}$ and $V_{12}$, propagating in the direction of the applied stress will deviate from the initial values according to the following equations ${ }^{2}$

$$
\begin{aligned}
& \rho_{0} V_{11}{ }^{2}=\rho_{0} V_{P}^{2}-\varepsilon_{l}(7 \lambda+14 \mu-6 l)-2 \varepsilon_{t}(3 \lambda-6 l-2 m) \\
& \rho_{0} V_{12}{ }^{2}=\rho_{0} V_{S}^{2}-\varepsilon_{l}\left(\lambda+2 \mu+\frac{m}{2}\right)-\varepsilon_{t}\left(2 \lambda+4 \mu+m+\frac{n}{2}\right)
\end{aligned}
$$

where $\rho_{0}$ is the initial density; $\varepsilon_{1}$ and $\varepsilon_{t}$ are the longitudinal and transverse strains; $\lambda$ and $\mu$ are the second-order elastic constants (Lame's constants); and $y, l, m$, and $n$ are Murnaghan's third-order elastic constants. If strains $\varepsilon_{1}$ and $\varepsilon_{t}$ satisfy the relations $\sigma_{11}=E \varepsilon_{1}$ and $\varepsilon_{t}=-v \varepsilon_{1}$ ( $E$ and $v$ are the Young's modulus and Poisson's ratio, respectively), Eq. (1) can be rewritten in the following form

$$
\begin{aligned}
& \rho_{0} V_{11}{ }^{2}=\rho_{0} V_{P}{ }^{2}-\frac{\sigma_{11}}{E}[(7 \lambda+14 \mu-6 l)-2 v(3 \lambda-6 l-2 m)] \\
& \rho_{0} V_{12}{ }^{2}=\rho_{0} V_{S}{ }^{2}-\frac{\sigma_{11}}{E}\left[\left(\lambda+2 \mu+\frac{m}{2}\right)-v\left(2 \lambda+4 \mu+m+\frac{n}{2}\right)\right]
\end{aligned}
$$

ACI Materials Journal, V. 109, No. 2, March-April 2012.

MS No. M-2009-395.R3 received March 24, 2011, and reviewed under Institute publication policies. Copyright (C) 2012, American Concrete Institute. All rights reserved, including the making of copies unless permission is obtained from the copyright proprietors. Pertinent discussion including author's closure, if any, will be published in the January-February 2013 ACI Materials Journal if the discussion is received by October 1, 2012. 
Parisa Shokouhi is a Research Scientist in Department 8 (Non-Destructive Testing) at Bundesanstalt für Materialforschung und Prüfung (BAM) (Federal Institute for Materials Research and Testing), Berlin, Germany. She received her $P h D$ in civil engineering from Rutgers University, New Brunswick, NJ. Her research interests include nondestructive testing (NDT) of construction materials, signal processing, and numerical modeling and simulation of NDT.

Andreas Zoëga is a PhD Candidate in Division 8.2 (Non-Destructive Damage Assessment and Environmental Measurement Methods) at BAM. He received his Dipl.-Engineer degree from the Technical University of Berlin (TU-Berlin), Berlin, Germany. His research interests include the automation of NDT methods for concrete inspection.

Herbert Wiggenhauser is the Head of Division 8.2 at BAM. He received his $P h D$ in physics from TU-Berlin in 1986. His research interests include the development and improvement of various NDT methods for evaluating concrete structures.

ACI member Gregor Fischer is an Associate Professor in the Department of Civil Engineering at the Technical University of Denmark, Copenhagen, Denmark. He received his PhD from the University of Michigan, Ann Arbor, MI. He is a member of ACI Committee 544, Fiber-Reinforced Concrete. His research interests include the mechanics and design of fiber-reinforced cement composites and their structural applications.

Therefore, acoustoelastic theory suggests a linear relationship between the applied uniaxial stress and the squared values of the longitudinal wave velocities. As long as the stressinduced changes are very small, one can use the approximations $V_{11}+V_{P}=2 V_{P}$ and $V_{12}+V_{S}=2 V_{S}$, which simplifies the equations governing the acoustoelastic effects to

$$
\begin{aligned}
& \frac{V_{11}-V_{P}}{V_{P}}=-\frac{\sigma_{11}}{2 E}\left[\frac{(7 \lambda+14 \mu-6 l)-2 v(3 \lambda-6 l-2 m)}{\lambda+2 \mu}\right] \\
& \frac{V_{12}-V_{S}}{V_{S}}=-\frac{\sigma_{11}}{2 E} \frac{1}{\mu}\left[\left(\lambda+2 \mu+\frac{m}{2}\right)-v\left(2 \lambda+4 \mu+m+\frac{n}{2}\right)\right]
\end{aligned}
$$

This equation indicates a linear relationship between the relative changes in velocities and the applied uniaxial stress. The velocities of ultrasonic waves of other propagation and polarization directions are described with similar equations. By measuring the ultrasonic wave velocities and using these equations, the third-order elastic constants can be reliably estimated.

The acoustoelastic theory and its applications in the evaluation of nonlinear material properties (that is, Murnaghan's elastic constants) of metallic substances have been extensively investigated over the past 50 years. ${ }^{3,4}$ The influence of texture, temperature, and microstructural changes on the third-order elastic constants of metals has been widely investigated. ${ }^{4}$ Very recently, Payan et al. ${ }^{5}$ determined the thirdorder elastic constants from the ultrasonic wave velocity measurements in uniaxially compressed concrete specimens.

\section{Microcracking}

The stress dependency of ultrasonic wave velocities in nonmetallic substances has also been studied. In rocks, this effect has been generally explained not by acoustoelasticity but by the microcracking theory. Sayers et al. ${ }^{6}$ measured ultrasonic wave velocities in three orthogonal directions on a cubic sample of Berea sandstone under uniaxial compressive stress (while maintaining a constant initial confining pressure). Using Hudson' ${ }^{7}$ crack model, they could calculate the distribution and orientation of microcracks within the sample from the velocity measurements.

\section{Stress dependency of wave velocities in concrete}

A decrease in ultrasonic pulse velocities in concrete at stress levels higher than $70 \%$ of the strength has been reported in a number of publications. ${ }^{8,9}$ Suaris and Fernando ${ }^{10}$ showed that the amplitude of the ultrasonic waves begins to decrease when the stress reaches approximately $40 \%$ of the strength, concluding that the amplitude is more sensitive to the state of stress than the velocity. This observation was confirmed by Nogueira and Willam, ${ }^{11}$ who used the changes in amplitude to estimate stress-induced microcrack growth in concrete. Kroggel and Wilhelm ${ }^{12}$ measured the changes in the amplitude (attenuation) of ultrasonic waves in a concrete specimen undergoing several loading-unloading cycles. They observed that the local minimum in the attenuation corresponds to the maximum load that the specimen has ever carried in its lifetime (beyond the early elastic region). They concluded that concrete preserves some form of stress memory in accordance with the Kaiser effect.

\section{RESEARCH SIGNIFICANCE}

The stress dependency of mechanical wave velocity in concrete under uniaxial compression is investigated herein. Instead of the ultrasonic (body) wave velocities, sonic surface wave velocities were measured. The sonic surface wave velocities proved to be highly sensitive to the level and direction of stress, as well as the amount of the permanent damage in concrete. These characteristics present the potential of the surface Rayleigh wave testing to be used for the nondestructive evaluation of stress and monitoring of progressive damage in concrete. Because the surface wave testing requires only one-sided access to the structure, this technique may also be used for field in-place measurements.

\section{EXPERIMENTAL INVESTIGATION}

The results of three different experiments-referred to herein as Experiments I, II, and III-are presented in this paper. Experiment I was carried out to study the stressinduced changes in surface wave velocities in concrete undergoing uniaxial compressive loading. Noncontact optical deformation measurements were conducted to capture the onset of cracking on the surface of the specimen. Experiment II was designed to investigate the stress memory effects in surface wave velocity measurements. Therefore, the concrete specimen was subjected to several loadingunloading cycles. By measuring the velocities during the unloading phases, the effects of stress and damage could be distinguished. A simple acoustic emission (AE) test was run parallel to the velocity measurements to record the microcracking activities at various load levels. Experiment III was conducted on a larger specimen. The larger size of the specimen made it possible to measure surface wave velocities along different directions and illustrate the direction dependency of the surface wave velocity measurements. A concise description of the test methods, followed by the main results of the three aforementioned experiments, are illustrated and discussed in this paper.

\section{Test specimens}

Prismatic specimens made of plain portland cement concrete with a water-cement ratio $(w / c)$ of 0.55 and a maximum aggregate size of $16 \mathrm{~mm}$ (5/8 in.) were used for all three experiments. The 28-day strength of the concrete mixture was measured as $42 \mathrm{MPa}$ (6092 psi). The specimens tested in Experiments I and II (Specimens I and II) had dimensions of $0.2 \times 0.2 \times 0.6 \mathrm{~m}(8 \times 8 \times 24$ in. $)$. The specimen 
tested in Experiment III (Specimen III) had dimensions of $0.4 \times 0.6 \times 1.0 \mathrm{~m}(16 \times 24 \times 36$ in.).

\section{Loading}

The compressive loading in Experiments I and II was applied using a $2 \mathrm{MN}$ (225 ton) loading machine. For Experiment III, a $25 \mathrm{MN}$ (2810 ton) loading machine was used. Specimens I, II, and III were subjected to six, nine, and four loading cycles, respectively. Each load cycle was applied in a number of predefined small load steps (stress-controlled), and wave velocity measurements were carried out at every load step. In Experiment I, the measurements were carried out only during the loading phases of the cycles. In Experiments II and III, the velocity measurements were carried out during the unloading phases as well.

\section{Measurement setup and test method for Experiment I}

Setup for surface wave velocity measurement-The measurement of surface wave velocities requires an appropriate impact source and at least two sensors, all lying on one line. The distance $D$ between the impact source and the near sensor should be large enough so that the surface waves are fully developed and the body waves are sufficiently attenuated (avoiding near-field effects). At the same time, the spacing between the two receivers should be small enough so the surface waves are not too attenuated at the far sensor (avoiding far-field effects). It is common to choose this spacing equal to $D$.

A small hammer was used as the impact source. As shown in Fig. 2, a total of nine sensors were mounted on the specimen-four on one side (Sensors I-1 to I-4) and the other five on the opposite side (Sensors I-5 to I-8). The surface wave velocity could be measured from the differences in the arrival times of surface waves between the sensor pairs (Sensors I-1 and I-2 and Sensors I-3 and I-4). Five other sensors-Sensors I-5 to I-9-were positioned on the opposite side. The spacing between the hammer and Sensors I-1 and I-3, as well as the distance between every two consecutive sensors on each side, was $0.1 \mathrm{~m}$ (4 in.). The sensor frame was designed to ensure sufficient and constant coupling of the sensors to the surface of the specimen. The data acquisition consisted of a personal computer with added pxi measuring cards. Using this system, a simultaneous recording of 12 channels with a sampling frequency of $1 \mathrm{MHz}$ and a resolution of 16 bits was possible. The initial Rayleigh wave velocity at the stress-free state was measured as $2372 \mathrm{~m} / \mathrm{s}(7782 \mathrm{ft} / \mathrm{s})$.

Test method-Surface wave velocities were measured at every load step (50 KN [5.62 ton]). To ensure the repeatability of the results and increase accuracy, the measurements were repeated 36 times at every load step. The loading was held constant during the measurements. Every measurement included the simultaneous recording at all nine sensors mounted on the specimen.

Deformation measurements using ARAMIS-As part of Experiment I, the surface deformation (strain) of the specimen was measured using a noncontact optical deformation measuring system called ARAMIS, ${ }^{13,14}$ as shown in Fig. 3. The study of stress-induced surface cracks was the main purpose of this measurement. The high-resolution imaging capabilities of ARAMIS made it possible to visualize the formation and widening of the stress-induced invisible

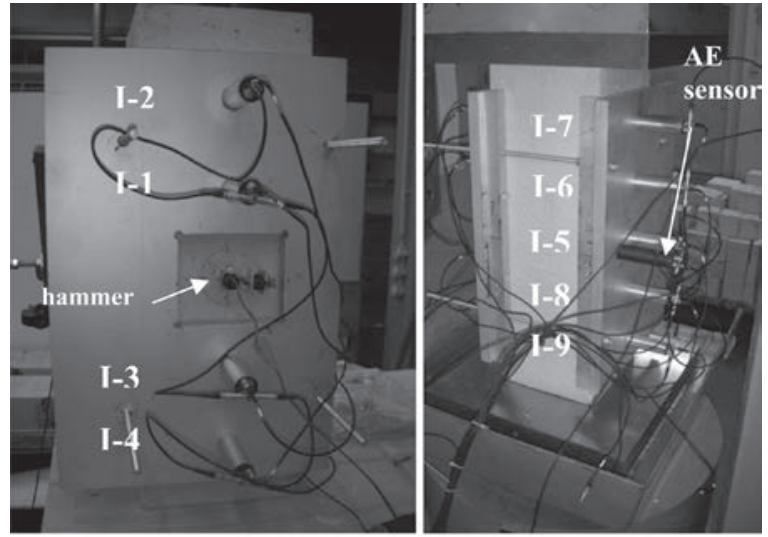

(a)

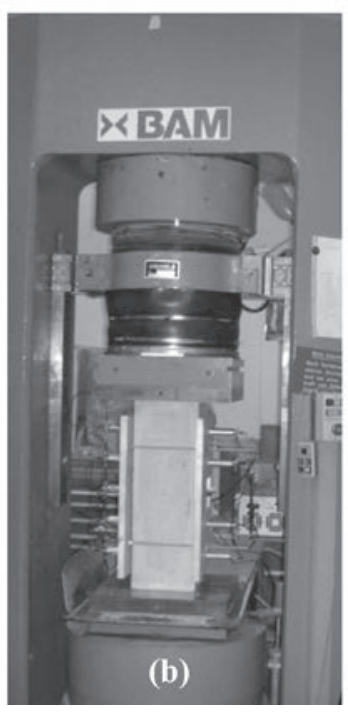

Fig. 2-(a) Arrangement of mounted sensors for surface wave velocity measurement in Experiments I and II; and (b) Specimen I being loaded in 2 MN (450 kip) loading machine.

cracks on the surface of the specimen long before they were visually recognizable.

ARAMIS operates based on three-dimensional (3-D) image correlation technology - a combination of twocamera synchronized image correlation and 3-D photogrammetry. The material being tested is viewed by a pair of highresolution, digital charge-coupled device (CCD) cameras, which measure the specimen's 3-D coordinates and the 3-D deformation. A random or regular pattern with good contrast is first applied to the surface of the test object, which deforms with the object. The deformation of this pattern under the applied load is recorded by the CCD cameras and then evaluated. The initial image processing defines unique correlation areas known as macroimage facets-typically 5 to 20 pixels square-across the entire imaging area. Each facet center is a measurement point that can be thought of as a strain rosette. These facets are tracked in each successive image with subpixel accuracy. Then, using photogrammetric principles, the 3-D coordinates of the entire surface of the specimen are precisely calculated. The results are the 3-D shape of the component, the 3-D displacements, and the plane strain tensor of every point on the surface of the object. ${ }^{15}$

The deformation measurements using ARAMIS were carried out in the laboratories of the Civil Engineering 


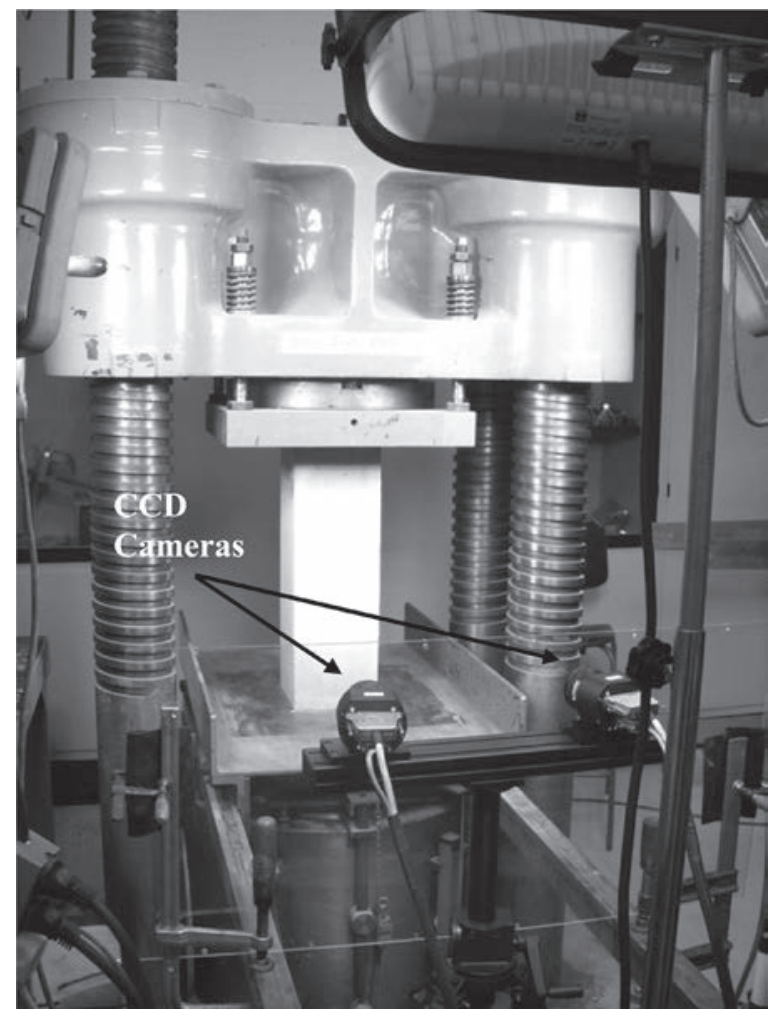

Fig. 3-Optical deformation measurements using ARAMIS system.

Department of Denmark Technical University. The concrete specimen used was different from the one used for velocity measurements but was the same size and was made of the same concrete mixture. A square-shaped imaging area of $0.2 \times 0.2 \mathrm{~m}(8 \times 8$ in. $)$ was considered for the measurements. The specimen was first painted a bright white color. Afterward, a random pattern of black dots was sprayed over the defined imagining area. Finally, the specimen was placed in a $2 \mathrm{MN}$ (225 ton) loading machine and loaded (loading cycles of Experiment I) while being continuously (every 5 seconds) imaged by ARAMIS cameras.

\section{Measurement setup and test method for Experiment II}

Setup for surface wave velocity measurement-The measurement setup used was the same as the one used in Experiment I. The initial Rayleigh wave velocity at the stress-free state was measured as $2410 \mathrm{~m} / \mathrm{s}$ (7907 ft/s).

$A E$ test setup-An $\mathrm{AE}$ test was conducted to monitor the formation of microcracks in the specimen as it underwent various loading cycles. A simple, in-house-built, onesensor AE test setup was used for this purpose. A broadband ultrasonic sensor with a frequency range of up to approximately $250 \mathrm{KHz}$ was used for this purpose. The AE sensor is marked in Fig. 2.

Test method-The AE measurements were conducted on Specimen II together with the surface wave velocity measurements. The AE was recorded as the loading was about to increase to the next loading step and continued after reaching the desired load level. The AE recording was stopped when no more AE events appeared in a 30-second time window after the last recorded event. The surface wave velocity measurements began only after the AE measurements were stopped.

\section{Measurement setup and test method for Experiment III}

Surface wave velocity measurement setup-Two different measurement setups were used: a mounted sensor array for time-of-flight measurements on one side and a laser-based noncontact measurement system for direction-dependency investigations on the opposite side of the specimen (Fig. 4). The sensor array included 12 accelerometers. The impact source was a small hammer driven by a solenoid. The impact source (a small hammer) was placed in the middle of the specimen. The sensors were arranged in four rows at an angle pitch of 30 degrees. In every row, three sensors were placed at distances of $7.5,12.5$, and $22.5 \mathrm{~cm}(3,5$, and 9 in.) from the impact source. All 12 sensors were recorded simultaneously with $1 \mathrm{MS} / \mathrm{s}$ and a resolution of 16 bits.

In the noncontact setup, a piezoelectric translator (piezo actuator) was used as the impact source. A voltage of half a sinus wave with a frequency of $25 \mathrm{kHz}$ induces a short impact on the concrete surface. The advantage of the piezo actuator is a constant time offset between the electrical pulse and the mechanical impact, leading to the high reproducibility of the impact. This property makes it possible to measure the wave velocities between the impact and a sensor rather than between two sensors (as in the case of mounted sensors). A laser vibrometer was used as the sensor. A unique feature of the laser vibrometer is that it can measure the surface-deflection velocity with sufficient accuracy, even from a distance of a couple of meters. This is especially important for measurements, where the load may exceed the strength of the specimen and the specimen may break. Another advantage of the laser vibrometer in the measurements is that the distance between the points used to measure the transit time is independent of the deformation of the specimen, as is the case when the sensors are applied directly at the surface. In front of the laser vibrometer, a scanning unit is attached, which deflects the laser beam via a mirror into different directions. The scanning unit is controlled by a personal computer (PC) equipped with a data acquisition card. This card can record two channels with $10 \mathrm{MS} / \mathrm{s}$ and a resolution of 12 bits (to measure the time difference between the electrical pulse and the signal of the laser vibrometer, both are recorded). The PC controls the timing of the measurements and the deflection of the laser beam to the measuring points and handles data acquisition and storage.

\section{Experiment I}

\section{RESULTS}

Stress dependency of surface wave velocities-The measured stress-induced changes in surface wave velocities in Specimen I are shown in Fig. 5(a). The surface wave velocities shown herein were measured between Sensors I-1 and I-2, as shown in Fig. 2(a). The change in velocity is normalized with respect to the velocity measured at the initial stress-free state. The change of velocity due to the deformation of specimens is one order of magnitude smaller than the stress-induced changes ${ }^{15}$ and, therefore, is ignored herein. The error bars show the standard deviation of all 36 measurements per load step. In every loading cycle, 

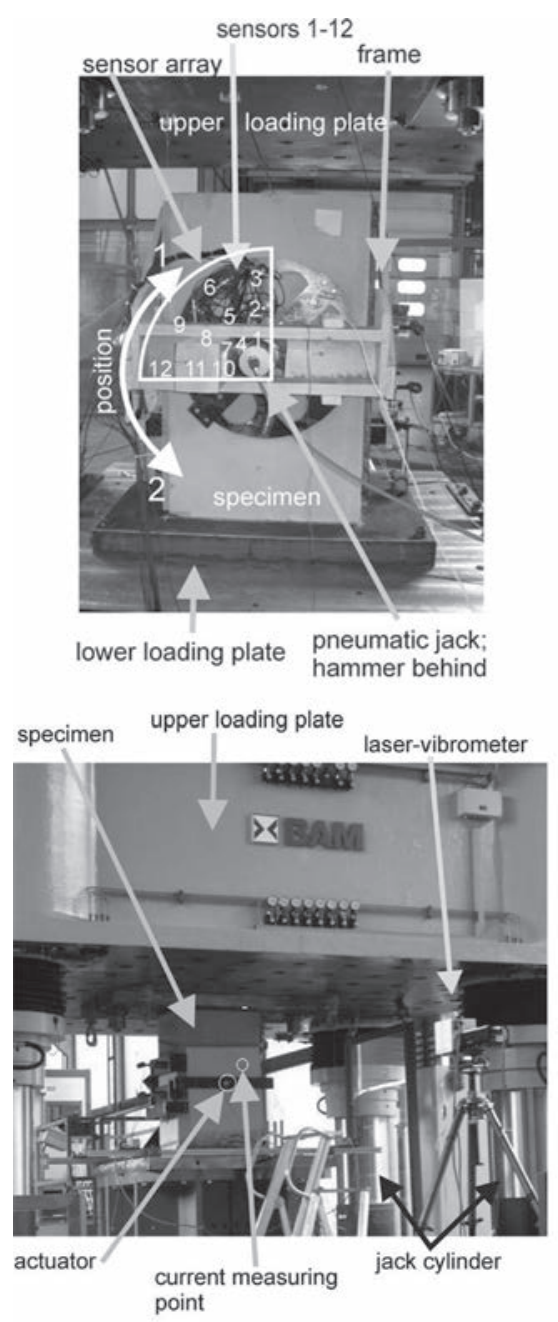

(a)
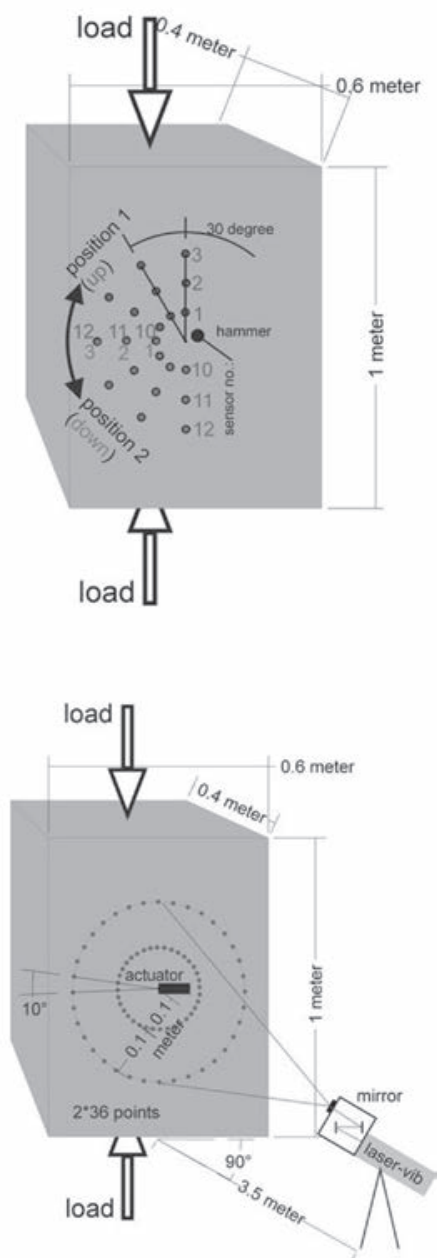

(b)

Fig. 4-Experimental setup for Experiment III: (a) sensor array; and (b) noncontact measurements using laser vibrometer.

the load step where the maximum previous load on concrete is exceeded (if there is any) is marked.

As shown in Fig. 5(a), surface wave velocities appear to be highly stress-dependent. The surface wave velocity-versusstress curve follows a general multi-phase trend:

- Phase I $(<10$ to $15 \%)$ : At the early load steps, the velocity increases very slightly or stays constant;

- Phase II (15 to $45 \%$ ): The velocity increases sharply as the load increases;

- Phase III (45 to 80\%): The velocity continues to increase but at a very slow rate compared to that of Phase II; and

- $\quad$ Phase IV (>80\%): The velocity starts to decrease.

The numbers given previously in parentheses indicate the corresponding approximate load range at each loading cycle expressed as the percentage of the failure load (that is, the load level at which the concrete specimen broke down), which will be referred to hereafter as the load or stress ratio. These four phases are marked in Fig. 5(a) for the very last load cycle. The specified approximate stress ratio ranges are for a specimen subjected to only one cycle of loading. In the case of multi-cycle loading, there may be additional changes in the slope of the velocity-stress curve, corresponding to the loading history (for example, an intermediate change of slope is seen at approximately $30 \%$ in Fig. 5(a)). This will be discussed in more detail in Experiment II.

The observed effect is believed to be the result of a number of mechanisms:

- At very low stress levels (Phase I), the concrete is still linear and the acoustoelastic effects are generally very small. From a microscopic point of view, the compressive stresses are not still large enough to close the existing microcracks. As a result, the velocity stays constant or changes only slightly with the applied stress.

- At low stress levels (Phase II), the acoustoelastic effects result in an increase in the measured velocities. From a microscopic point of view, the compressive stresses result in the gradual closure of microcracks, with normals parallel to the direction of loading. ${ }^{11,16-17}$ This phenomenon results in a gradual increase in the stiffness and, consequently, to an increase in the surface wave velocities measured parallel to the loading axis.

- At higher load steps (Phase III), the existing microcracks parallel to the direction of the loading (with normals perpendicular to the loading axis) start to widen and new microcracks are formed. The widening and development of microcracking result in a gradual reduction 


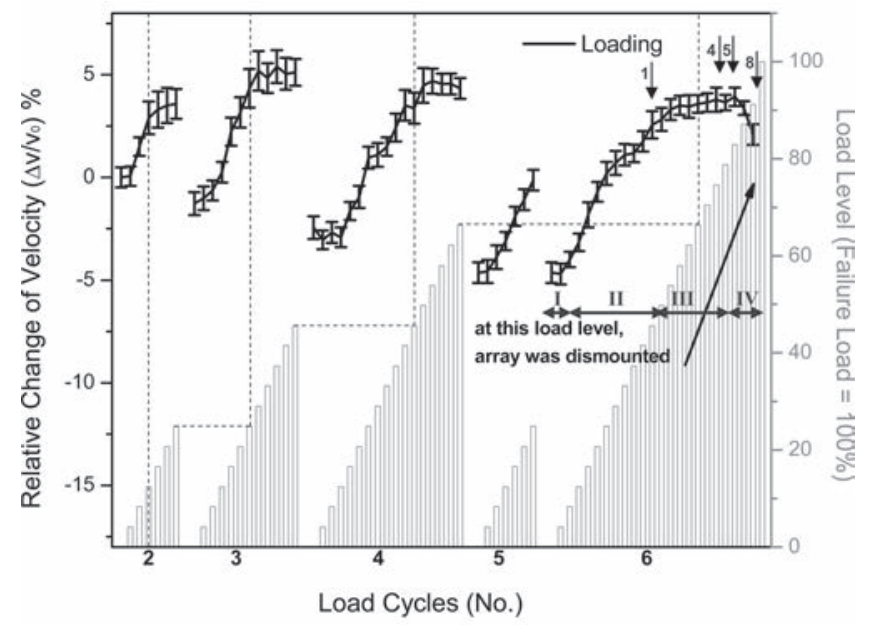

(a)

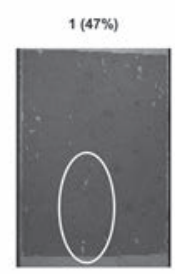

$5(81 \%)$

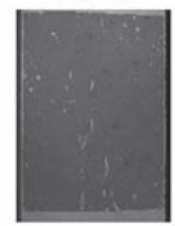

9 (97\%)

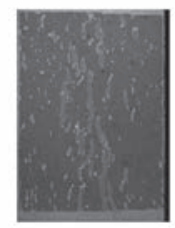

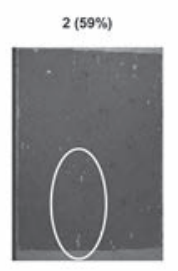

$6(85 \%)$

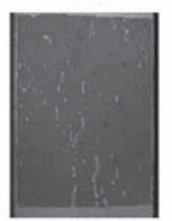

$10(98 \%)$

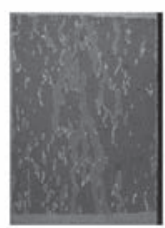

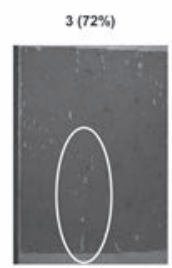

7 (89\%)

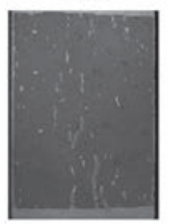

11 (99\%)

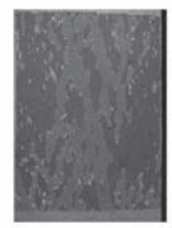

(b)
Fig. 5-Results of Experiment I: (a) stress-dependency and stress-memory effects of surface wave velocity measurements; and (b) widening of surface vertical cracks illustrated in principal strain contour plots.

in the mechanical properties and, consequently, the surface wave velocities in concrete.

- At critical load steps (Phase IV), the microcracks develop into macrocracks and the velocities sharply decrease.

The aforementioned progressive microcracking process in Phases III and IV visualized using the ARAMIS system is illustrated in Fig. 5(b). The principal strain distribution across the $0.2 \times 0.2 \mathrm{~m}(8 \times 8$ in.) imaged area at 12 different load steps (of the last loading cycle) is illustrated in Fig. 5(b). The selected distribution plots are numbered from 1 to 12 with stress ratios given in parentheses. The corresponding locations of four selected plots (Plots 1, 4, 5, and 8) are marked on the velocity-stress curves. The first evidence of vertical microcracks (parallel to the load direction) appears at approximately $50 \%$ of the failure load. New cracks develop and the existing cracks continue to widen at later load steps. After $80 \%$, the cracks join together and form macrocracks and eventually visible cracks. The deformation measurements confirmed the hypothetical explanations given previously for the observed effects at later load steps.

Stress memory effects-The surface wave velocity measurements show stress memory effects (that is, the velocity-stress relationship is dependent on the stress history of the specimen at the time of measurement). For example, this effect is evident when the curves for Loading Cycles 2 and 5 are compared. Whereas the loading cycles were identical, the curves look quite different because of the difference in the stress history of the specimen. The observed effect is in agreement with the Kaiser effect. According to Kaiser, as long as the maximum previous load on concrete is not exceeded (unless the material is unstable and close to failure), no new microcracks develop. Therefore, the velocities increase only due to acoustoelasticity (or the closure of microcracks). Once the maximum previous load is exceeded, new microcracks form. This formation of microcracks results in a change of slope of the surface wave velocity-stress curves.

Effect of progressive damage-A comparison of the measured surface wave velocities at the stress-free state for different load cycles (that is, velocities measured at the beginning of each cycle) reveals that the surface wave velocities decrease with an increase in internal damage within concrete. The stress-free velocities are nearly the same for Loading Cycles 5 and 6 because the maximum load on concrete in Loading Cycle 5 was not exceeded and no new microcracks were developed.

\section{Experiment II}

Effects of stress and damage-In Experiment II, the wave velocities were also measured during the unloading phases of the loading cycles (at $100 \mathrm{kN}$ [22.4 kip] load steps). The measurement results for Loading Cycles 2 to 9 are shown in Fig. 6. Because of an error that occurred during the application of the very first load cycle (one load step was skipped), the corresponding results of this load cycle are not included herein.

The surface wave velocity-versus-stress diagrams for the loading and unloading phases are almost identical for the first five loading cycles, where the stress remains below $45 \%$. The difference between the loading and unloading curves becomes noticeable first in Loading Cycle 6 (60\%). Not having exceeded the maximum previous load, the difference diminishes again for Loading Cycle 7 . The largest difference was measured for Loading Cycle 8. Because no new damage occurs during the unloading phases, the changes in velocities over the unloading phases are only stress-induced. Therefore, as long as the level of irrecoverable damage is low (the stress ratio is below 45\%), the unloading and loading curves remain in good agreement. Once the material suffers permanent damage (microcracking), the unloading curves differ from those measured during the loading phase. The higher the level of the damage, the larger the difference between the loading and unloading curves. In other words, the difference between the two curves indicates the level of irrecoverable damages.

Effect of progressive damage (microcracking)-The recorded AE events superimposed on the velocity measurements made during Experiment II are shown in Fig. 7. The sudden jumps in the number of $\mathrm{AE}$ events occur when the loading reaches beyond the previous maximum load level 


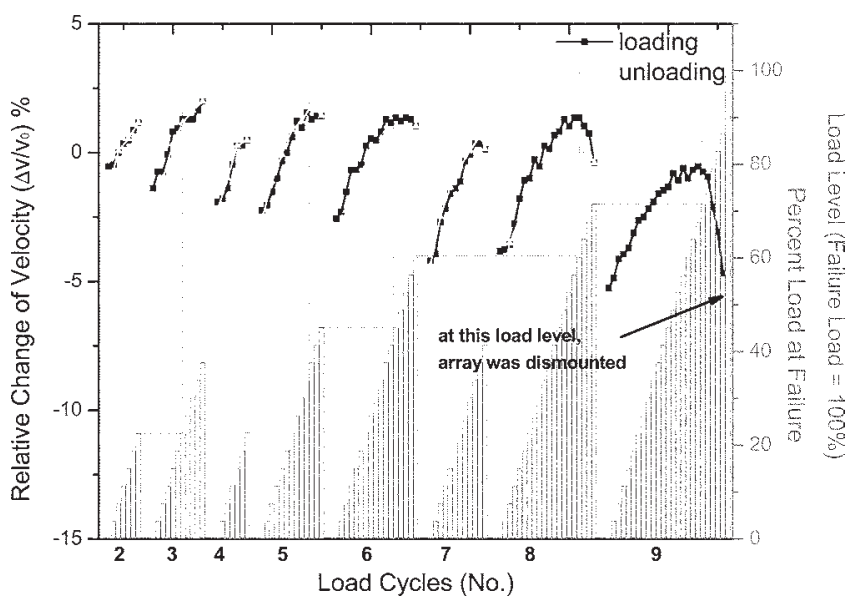

Fig. 6-Effects of stress and damage on surface wave velocity measurements in Experiment II.

and new microcracks are developed. They also correspond to the changes of slopes in the velocity-stress curves. With the exception of the first two load cycles, the amount of decrease in the stress-free surface wave velocities after the application of each load cycle is proportional to the number of recorded $\mathrm{AE}$ events. In other words, new microcracking results in the flattening of the velocity-stress curve and the decrease in wave velocity is proportional to the number of existing microcracks within concrete. It should be noted that the unexpectedly large number of events during the first two load cycles include the unwanted events (noise) resulting from the loading plate sitting on the rough surface of the specimen.

\section{Experiment III (PK3)}

Effects of stress and damage-The surface wave velocities measured by the sensor array mounted on Specimen III are shown in Fig. 8. Because of the larger size of the specimen, the surface wave velocities could be measured with a higher confidence level, as reflected in the smaller size of the error bars. Otherwise, the effects are quite similar to those observed in the smaller specimens of Experiments I and II. The initial Rayleigh wave velocity at the stress-free state was measured as $2156 \mathrm{~m} / \mathrm{s}(7073 \mathrm{ft} / \mathrm{s})$.

In Loading Cycle 1, a clear difference between the surface wave velocities measured during the loading and unloading phases is observed. This is expected because the load ratio had reached approximately $50 \%$. The second loading cycle is noteworthy. In this cycle, the load was increased to $7.5 \mathrm{MN}$ (843 ton) (approximately 107\% of the failure load), very close to the strength of the concrete specimen, resulting in the first visible cracks at the edges of the specimen. This load step could only be held long enough to do the measurements; if held slightly longer, the specimen would have collapsed. As expected, the initial slope of the velocity-stress curve for the loading phase of Loading Cycle 2 is equal to that of the unloading phase of Loading Cycle 1. There is a change in slope as the stress reaches beyond the maximum previous load level, followed by a sharp drop after the maximum load. Because of the induced damages, the velocities over the unloading phase are significantly lower than the corresponding values in the loading phase.

In Loading Cycle 3, the velocity and slope over the entire cycle measure considerably lower than those measured in the first cycle. The maximum velocity does not even

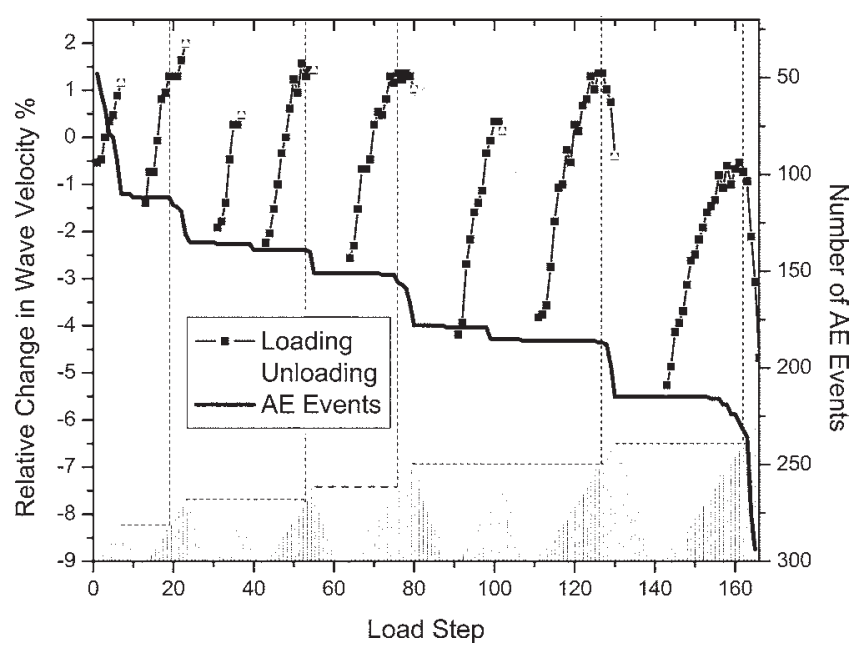

Fig. 7-Results of AE test superimposed on velocity measurements of Experiment II.

reach the initial value (corresponding to the stress-free state). In Loading Cycle 4 , the velocity rises for loads up to $5.5 \mathrm{MN}$ (618 ton) (approximately $79 \%$ of the failure load) and exceeds the values of Loading Cycle 3 at higher loads. However, it did not exceed the pre-overload values. At greater than 5.5 MN (618 ton) (approximately 79\% of the failure load), the surface wave velocity falls again. Due to safety reasons, the sensor array was removed at $6 \mathrm{MN}$ (674 ton) (approximately 86\% of the failure load), and the specimen broke at $7 \mathrm{MN}$ (787 ton) (the failure load).

Anisotropy of surface wave velocities-Surface wave velocities measured by a laser vibrometer along different directions at three load ratios of 50, 81, and 107\% (maximum load) of Loading Cycle 2 are shown in the polar graph of Fig. 9. The velocity values are normalized with respect to the stress-free state, depicted by a thick circle. It can be seen that at higher stress levels, this circle takes an elliptical shape with major and minor axes, parallel and perpendicular to the direction of loading. This indicates that the maximum increase in surface wave velocities occurs in the direction of the load, whereas the maximum decrease happens in the perpendicular direction. This is expected because the closure of microcracks results in the increase of velocities parallel to the loading, whereas the development of vertical cracks results in the decrease in the velocities measured perpendicular to the loading. ${ }^{16,17}$ Between 0 and $50 \%$, because of the closure of microcracks, the primary effect is the increase in surface wave velocities measured parallel to the loading. Between 50 and $81 \%$, when the microcrack-induced damage prevails, the primary effect is the decrease in the velocities measured perpendicular to the direction of loading. Parallel to the load, the velocity remains almost constant (the flattening of the velocity-stress curve). The most dramatic change occurs between 81 and $107 \%$, when the velocities in the perpendicular direction drop sharply.

\section{CONCLUSIONS}

The experimental results presented in this paper can be summarized in the following points:

- The velocity of sonic surface waves in concrete under uniaxial compression is highly stress-dependent.

- At low stress levels, the velocity increases with stress (due to acoustoelastic effects and the closure of the existing microcracks). At load ratios greater 


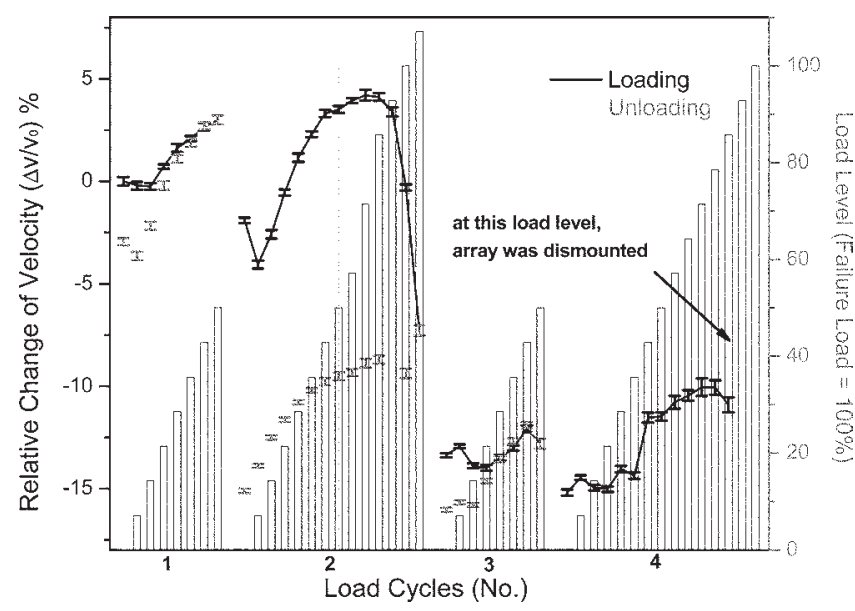

Fig. 8-Effects of stress and damage on surface wave velocity measurements in Experiment III.

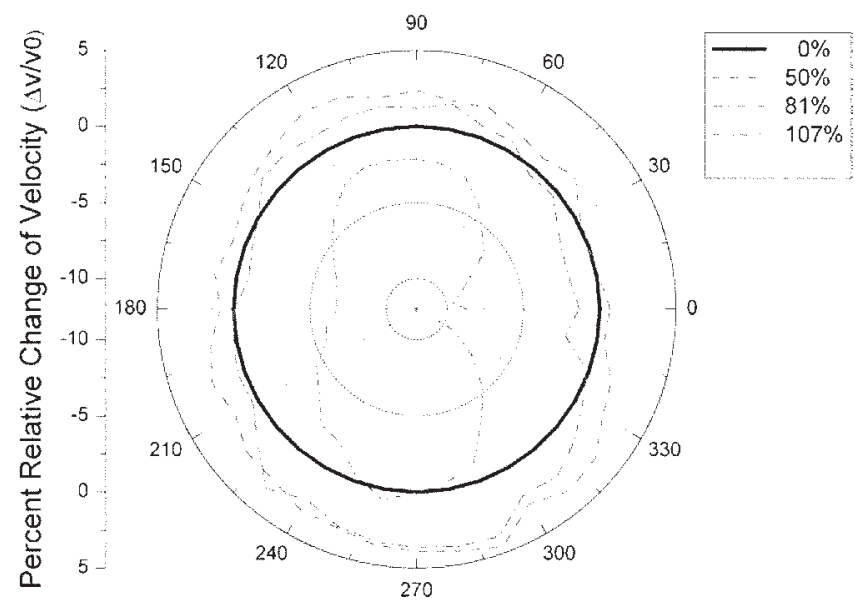

Fig. 9-Direction dependency of surface wave velocity measurements in second load cycle of Experiment III.

than approximately $45 \%$, the curve flattens (due to progressive microcracking with normals perpendicular to the loading axis), followed by a drop at stress ratio levels greater than $80 \%$ (due to the development of microcracks into macrocracks).

- The velocity measurements show a stress-memory effect in good agreement with the Kaiser effect.

- The difference between the velocity-stress curves in the loading and unloading phases indicates the level of irrecoverable damage in the concrete. In permanently damaged concrete, the surface wave velocities measure lower and the difference between the loading and unloading curves is larger.

- Under anisotropic loading, the velocity changes are anisotropic. The velocities increase and decrease the most when measured parallel and perpendicular to the loading, respectively.

- The sensitivity of sonic surface wave velocities to the level of damage and stress in concrete may be used in applications such as the inspection of prestressed components and quantifying distributed damage due to ASR.

\section{ACKNOWLEDGMENTS}

The authors are grateful to A. Barner from BAM VII.2 and F. Weise from BAM VII.1 for their invaluable help and support in carrying out the experiments. This study is partially supported by a grant from the Alexander von Humboldt (AvH) Foundation. This support is gratefully acknowledged.

$E \quad=$ Young's modulus

\section{NOTATION}

$l, m, n=$ Murnaghan's third-order elastic constants

$V_{11}=$ velocity of longitudinal ultrasonic waves (after application of load)

$V_{12}=$ velocity of transversal ultrasonic waves (after application of load)

$V_{P} \quad=$ initial (stress-free) compression wave velocity

$V_{S} \quad=$ initial (stress-free) shear wave velocity

$\varepsilon_{1} \quad=$ longitudinal strain

$\varepsilon_{t} \quad=$ transversal strain

$\lambda, \mu=$ second-order elastic constants (Lame's constants)

$v \quad=$ Poisson's ratio

$\rho_{0} \quad=$ initial density

$\sigma_{11}=$ uniaxial normal stress

\section{REFERENCES}

1. Hughes, D. S., and Kelly, J. L., "Second-Order Elastic Deformation of Solids," Physical Review, V. 92, No. 5, 1953, pp. 1145-1149.

2. Takahashi, S., and Motegi, R., "Stress Dependency on Ultrasonic Wave Propagation Velocity-Part I: Analysis by the Eulerian Viewpoint of Ultrasonic Wave Velocity in the Uniformly Deformed Isotropic Solid," Journal of Materials Science, V. 22, 1987, pp. 1850-1856.

3. Bergman, R. M., and Shahbender, R. A., "Effects of Statically Applied Stresses on the Velocity of Propagation of Ultrasonic Waves," Journal of Applied Physics, V. 29, 1958, pp. 1736-1738.

4. Hauk, V., Structural and Residual Stress Analysis by Nondestructive Methods: Evaluation-Application-Assessment, Elsevier Science B. V., Amsterdam, the Netherlands, 1997, $654 \mathrm{pp}$.

5. Payan, C.; Garnier, V.; and Moysen, J., "Determination of Third Order Elastic Constants in a Complex Solid Applying Coda Wave Interferometry," Applied Physics Letters, V. 94, No. 1, 2009, 3 pp.

6. Sayers, C. M.; Van Munster, J. G.; and King, M. S., "Stress-Induced Ultrasonic Anisotropy in Berea Sandstone," International Journal of Rock Mechanics, V. 27, No. 5, 1990, pp. 429-436.

7. Hudson, J. A., "Wave Speeds and Attenuation of Elastic Waves in Materials Containing Cracks," Geophysical Journal of the Royal Astronomical Society, V. 64, 1981, pp. 133-150.

8. Raju, N. K., "Small Concrete Specimens under Repeated Compressive Loads by Pulse Velocity Technique," ASTM Journal of Materials, V. 5, No. 2, 1970, pp. 262-273.

9. Shah, S. P., and Chandra, S., "Mechanical Behavior of Concrete Examined by Ultrasonic Measurements," ASTM Journal of Materials, V. 5, No. 3 , 1970, pp. 550-563.

10. Suaris, W., and Fernando, V., "Detection of Crack Growth in Concrete from Ultrasonic Intensity Measurements," Materials and Structures, V. 20, 1987, pp. 214-220.

11. Nogueira, C. L., and Willam, K. J., "Ultrasonic Testing of Damage in Concrete under Uniaxial Compression," ACI Materials Journal, V. 98, No. 3, May-June 2001, pp. 265-275.

12. Kroggel, O., and Wilhelm, T., "Stress-Memory of Concrete-Ultrasonic Investigations," 2nd International RILEM Symposium on Advances in Concrete through Science and Engineering, RILEM Publications SARL, 2006, pp. 207-224.

13. Tyson, J.; Schmidt, T.; and Galanulis, K., "Biomechanics Deformation and Strain Measurements with 3D Image Correlation Photogrammetry," Experimental Techniques, V. 26, No. 5, Sept. 2002, pp. 39-42.

14. "ARAMIS Optical 3D Deformation Analysis," GOM mbH, 2005. (http://www.trilion.com/Products/aramis.html)

15. Shokouhi, P.; Niederleithinger, N.; Zoëga, A.; Barner, A.; and Schöne, D., "Using Ultrasonic Coda Wave Interferometry for Monitoring Stress-Induced Changes in Concrete," EEGS Annual Meeting SAGEEP, Keystone, CO, Apr. 2010. (CD-ROM)

16. Berthaud, Y., "Damage Measurements in Concrete Via an Ultrasonic Technique-Part I Experiment," Cement and Concrete Research, V. 21, 1991a, pp. 73-82.

17. Berthaud, Y., "Damage Measurements in Concrete Via an Ultrasonic Technique-Part II Modeling," Cement and Concrete Research, V. 21, 1991b, pp. 219-228. 